\title{
Ion-Exchange Voltammetry at Polymer Film-Coated Nanoelectrode Ensembles
}

\author{
Paolo Ugo, ${ }^{* \dagger}+$ Ligia M. Moretto, ${ }^{\dagger}$ Sara Bellomi, ${ }^{\dagger}$ Vinod P. Menon, ${ }^{\ddagger}$ and Charles R. Martin*, \\ Department of Physical Chemistry, University of Venice, Venice, Italy, and Department of Chemistry, Colorado State \\ University, Fort Collins, Colorado 80523-1872
}

\begin{abstract}
Ensembles of nanoscopic disk-shaped electrodes have been shown to offer enhancements in electroanalytical detection limits relative to electrodes of macroscopic dimensions (e.g., disk electrodes with diameters of $\sim 1$ $\mathrm{mm}$ ). Enhancements in electroanalytical detection limits have also been observed at macroscopic electrodes that have been coated with films of ion-exchange polymers. In this paper we combine these two concepts. We demonstrate that a nanoelectrode ensemble (NEE) that has been coated with a thin film of the Kodak ion-exchange polymer AQ 55 shows enhanced electroanalytical detection limits relative to the uncoated NEE and to the coated macroscopic electrode. To our knowledge, this is the first investigation of the electrochemistry, and the electroanalytical advantages, of polymer film-coated NEEs.
\end{abstract}

A new approach for preparing ensembles of nanoscopic diskshaped electrodes has recently been described. ${ }^{1}$ These nanoelectrode ensembles (NEEs) are prepared using a membranebased method, ${ }^{2}$ in which the pores in a nanoporous membrane act as templates for the nanoelectrodes. The membranes employed contain monodisperse, cylindrical pores that run the complete thickness of the membrane. A nanoscopic wire of gold is deposited within each pore of the membrane. ${ }^{1}$ The disk-shaped ends of these Au nanowires (at one face of the membrane) define the ensemble of nanodisk electrodes. Ensembles of Au nanodisks with diameters as small as $10 \mathrm{~nm}$ have been prepared using this template-based method. ${ }^{1}$

The number of $\mathrm{Au}$ nanodisks per square centimeter of membrane surface area is determined by the density of the pores in the template membrane. Typically these membranes have high pore densities; for example, the membranes used to prepare the NEEs described in this paper had a pore density of $6 \times 10^{8}$ pores $\mathrm{cm}^{-2}$. As a result, these NEEs operate in the "total overlap" electrochemical limiting case, ${ }^{1,3}$ in which the diffusion layer created at each disk-shaped element overlaps with the diffusion layers created at its neighboring elements. As a consequence of this total overlap situation, conventional peak-shaped voltammograms are obtained at these NEEs.

It is well known that NEEs operating in this total overlap regime can show enhanced electroanalytical detection limits relative to an electrode of conventional dimensions (e.g., a disk-

\footnotetext{
+ University of Venice.

₹ Colorado State University.

(1) Menon, V. P.; M artin, C. R. Anal. Chem. 1995, 67, 1920-1928.

(2) Martin, C. R. Science 1994, 266, 1961-1966.

(3) Cheng, I. F.; Whiteley, L. D.; M artin, C. R. Anal. Chem. 1989, 61, 762766 .
}

shaped electrode with a diameter of $1 \mathrm{~mm}$; we call such electrodes "macroelectrodes").1,3 This enhancement in detection limit occurs because Faradaic currents are proportional to the geometric area of the NEE, while the background signal (the double-layer charging current) is proportional only to the sum of the active electrode area. We have shown that the detection limit is decreased by a factor equivalent to the fractional electrode area, which is the sum of the active electrode area divided by the geometric area of the NEE.1,3

It occurred to us that detection limits at the NEE could be further enhanced by coating the NEE surface with a film of an ion-exchange polymer. This is because an ion-exchange polymer film can preconcentrate an electroactive counterion at the substrate electrode surface; the term "ion-exchange voltammetry" has been used to describe this preconcentration effect.4,5 Hence, if an ion-exchange polymer film is coated onto a NEE surface, the electroanalytical detection limit should be enhanced by both the signal-to-background advantage inherent in the NEE ${ }^{1,3}$ and the preconcentration effect of ion-exchange voltammetry.,5

In this paper we describe results of electrochemical experiments at NEEs that have been coated with a film of Eastman Kodak's AQ 55 poly(ester sulfonate) cation-exchange polymer. ${ }^{6-8}$ This polymer has been shown to preconcentrate electroactive cations at conventional macroelectrode surfaces. ${ }^{6}$ We have found that electroanalytical detection limits for electroactive cations at these polymer-modified NEEs are enhanced relative to detection limits obtained at the uncoated NEE or at a polymer-modified macroelectrode.

\section{EXPERIMENTAL SECTION}

Materials. $\mathrm{Ru}\left(\mathrm{NH}_{3}\right)_{6} \mathrm{Cl}_{3}$ (M atthey Bishop) was recrystallized as per ref 9. (Ferrocenylmethyl)dimethylamine (Aldrich) was reacted with methyl iodide to form the quaternary ammonium iodide. This was then converted to (ferrocenylmethyl)trimethylammonium hexafluorophosphate $\left(\mathrm{FA}^{+} \mathrm{PF}_{6}{ }^{-}\right)$using $\mathrm{KPF}_{6 .}{ }^{10}$ All solutions were prepared using purified water obtained by passing house-distilled water through a M illi-Q (M illipore) water purification system. Supporting electrolytes were analytical reagent grade and were used as received.

The NEEs were prepared from polycarbonate filtration membranes (Poretics) having a pore diameter of $30 \mathrm{~nm}$. Au nanowires

\footnotetext{
(4) Szentirmay, M. N.; M artin, C. R. Anal. Chem. 1984, 56, 1898-1902.

(5) Espenscheid, M. W.; M artin, C. R. Electroanalysis 1989, 1, 93-95.

(6) Wang, J.; Golden, T. Anal. Chem. 1989, 61, 1397-1400.

(7) Gennet, T.; Purdy, W. C. Anal. Chem. 1990, 62, 2155-2158.

(8) Hanzlik, J.; Ugo, P.; Daniele, S.; Mazzocchin, G. A. J. Electroanal. Chem. 1996, 404, 89-97.

(9) Pladziewicz, R.; M eyer, T.; B roomhead, J . A.; Taube, H. Inorg. Chem. 1973, $12,639-643$.

(10) Lombardo, A.; Bieber, T. I. J. Chem. Educ. 1983, 60, 1080-1081.
} 
were deposited within the pores of these membranes using the electroless deposition procedure described previously. ${ }^{1}$ The geometric area of the NEE exposed to solution was $0.08 \mathrm{~cm}^{2}$. The fractional electrode area for these NEEs has been shown to be 0.0045. ${ }^{1}$

Film-Coating Procedure. A 30\%aqueous dispersion of the AQ 55 polymer was obtained from Eastman. This dispersion was diluted with distilled water to yield a dispersion that was $1 \%$ in AQ 55. The surface of the NEE was coated by applying $2 \mu \mathrm{L}$ of the $1 \%$ dispersion to the $0.08 \mathrm{~cm}^{2}$ surface of the NEE and allowing the solvent (water) to evaporate at room temperature. As described in detail in our previous paper, ${ }^{1}$ the NEE surface that is exposed to solution is defined by a circular hole that is cut into a piece of plastic tape that covers the surface of the NEE. This hole acts as a beaker to confine the polymer solution. As a result, there is no evidence that polymer solution spreads to the tape. Hence, the reproducibility of solution deposition is excellent. After evaporation of the solvent, the resulting film was then heated for $2 \mathrm{~h}$ at $60^{\circ} \mathrm{C}$. This procedure has been shown to yield strongly adherent, water-insoluble films of AQ $55^{7,8}$

Analogous films were cast onto the surfaces of conventional glassy carbon (Tokai, Tokyo, Japan) and Au disk electrodes. These macroelectrodes also had areas of $0.08 \mathrm{~cm}^{2}$. The polymer solution uniformly wets the macroelectrode surface and is confined to this surface. As a result, again, there is no evidence for spreading of the polymer solution to the surrounding insulating phase; again, the reproducibility of film deposition is excellent.

The density of the AQ 55 polymer was obtained by weighing a rectangular piece of the film, prepared under identical conditions as the films used in the electrochemical studies, that had macroscopic dimensions $(2.5 \mathrm{~cm} \times 2.5 \mathrm{~cm}, 0.053 \mathrm{~cm}$ thick $)$. A density of $1.34 \mathrm{~g} \mathrm{~cm}^{-3}$ was obtained. This density was used to calculate the average film thickness for the modified electrodes studied here. A film thickness of $1.9 \mu \mathrm{m}$ was obtained. However, this is a dry film thickness. To assess the extent of swelling in the electrolyte solution, a piece of the film with macroscopic dimensions was immersed for $4 \mathrm{~h}$ into a $10^{-3} \mathrm{M}$ solution of $\mathrm{NaNO}_{3}$. The thickness increased by $\sim 70 \%$ This is not surprising given the fact that this is an un-cross-linked ion-exchange polymer.

B ecause of this extensive solvent swelling, the concentrations of the ions in the polymer film were calculated in terms of the mole fraction of $\mathrm{SO}_{3}{ }^{-}$sites occupied by a particular ion. This mole fraction convention is typically used to express concentrations of ions in ionexchange polymer films and was used in our prior work on Nafion films. ${ }^{4}$ The advantage of this approach is that concentrations calculated in this way do not require a measurement of film thickness.

Experimental Protocol. The electrochemical cell consisted of the AQ 55-coated (or other) working electrode, a Pt spiral counter electrode, and an $\mathrm{Ag} / \mathrm{AgCl}$ reference. An AMEL 553 potentiostat in conjunction with an AM EL 568 function generator and a Yokogawa $3023 X-Y$ recorder was used to obtain the voltammetric data. An EG\&G-PAR 384 B was used for the differential pulse voltammetric measurements. Solutions were degassed with purified $\mathrm{N}_{2}$ prior to electrochemical measurements.

The procedures used to equilibrate the film-coated electrode with the electroactive cation, and to obtain the partition isotherm data, were identical to those used previously. ${ }^{4}$ B riefly, the freshly prepared AQ 55-coated electrode was immersed into a solution that contained the desired concentrations of the electroactive cation and supporting electrolyte. The electroactive cation was allowed to partition into the AQ 55 film, and the course of this equilibrium process was followed by periodically scanning through the redox wave of the cation. During the equilibration process, the peak currents for such voltammograms increased with time.

When partition equilibrium is achieved, there is no further change in peak current with time. Equilibration required a maximum of $\sim 75 \mathrm{~min}$ for $\mathrm{Ru}\left(\mathrm{NH}_{3}\right)_{6}{ }^{3+}$ and $\sim 60 \mathrm{~min}$ for $\mathrm{FA}^{+}$. The equilibrium quantity of electroactive cation partitioned into the film was obtained from the charge associated with such an equilibrium voltammogram. It is important to stress that, as per our previous work, ${ }^{4}$ the equilibrium voltammogram was obtained while the electrode was still immersed in the loading solution. The electrode was then equilibrated with a solution containing the next (higher) concentration of the electroactive cation. This process was repeated for the desired number of solution concentrations. As per our previous work, ${ }^{4}$ because the partition coefficients are so large, the contribution to the total measured current from electroactive cation dissolved in solution is negligibly small.

\section{RESULTS AND DISCUSSION}

Ion-Exchange Voltammetry with an AQ 55-Coated Glassy Carbon Electrode. Prior to investigating the polymer-modified NEEs, the electrochemical behavior of (ferrocenylmethyl)trimethylammonium $\left(\mathrm{FA}^{+}\right)$and $\mathrm{Ru}\left(\mathrm{NH}_{3}\right)_{6}{ }^{3+}$ at an $\mathrm{AQ}$ 55-coated glassy carbon macroelectrode was studied. This was necessary because no quantitative data on the preconcentration effect for these electroactive cations in AQ 55 are currently available in the literature.

Preconcentration of $\mathrm{FA}^{+}$at the Coated Glassy Carbon Electrode. Figure 1 compares voltammograms for $\mathrm{FA}^{+}$at an $\mathrm{AQ}$ 55-coated electrode and at a bare glassy carbon electrode. The film-coated electrode (Figure 1A) shows the characteristic ${ }^{11}$ increase in the voltammetric current with time, corresponding to the loading of the polymer film with the electroactive cation. The final voltammogram in Figure $1 \mathrm{~A}$ is equivalent to the voltammogram associated with maximal loading of $F A^{+}$into the AQ 55 film. ( $M$ aximal loading of $\mathrm{FA}^{+}$at this concentration is achieved in $\sim 15$ min.) The dramatically higher peak current at the AQ 55-coated electrode (note the difference in current sensitivities) clearly shows that this polymer preconcentrates $\mathrm{FA}^{+}$.

The effect of scan rate on the shape of the voltammogram at the film-coated electrode is as would be expected.11 At the lower scan rate $\left(5 \mathrm{mV} \mathrm{s}^{-1}\right)$, the voltammogram is characteristic of a surface-confined process, indicating that the entire film is oxidized and then re-reduced during the voltammetric scan (finite diffusion). In contrast, the voltammogram at the higher scan rate (200

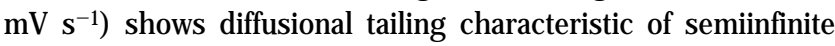
linear diffusion in the film. ${ }^{11}$ This transition from finite to semiinfinite diffusion can be seen in plots of peak currents vs scan rate $(v)$ and square-root of scan rate $\left(v^{1 / 2}\right)$ for the $\mathrm{FA}^{+}$-loaded $\mathrm{AQ}$ 55 films (not shown). Peak currents for the low scan rate voltammograms are linearly related to $v$, whereas the high scan rate voltammograms show $v^{1 / 2}$ dependence.

Because the slow scan rate voltammograms cause quantitative electrolysis of the $\mathrm{FA}^{+}$in the $\mathrm{AQ} 55$ film, the area under the oxidation wave can be used to calculate the number of moles of

(11) M artin, C. R.; Rubinstein, I.; Bard, A. J. J. Am. Chem. Soc. 1982, 104, 48174824. 


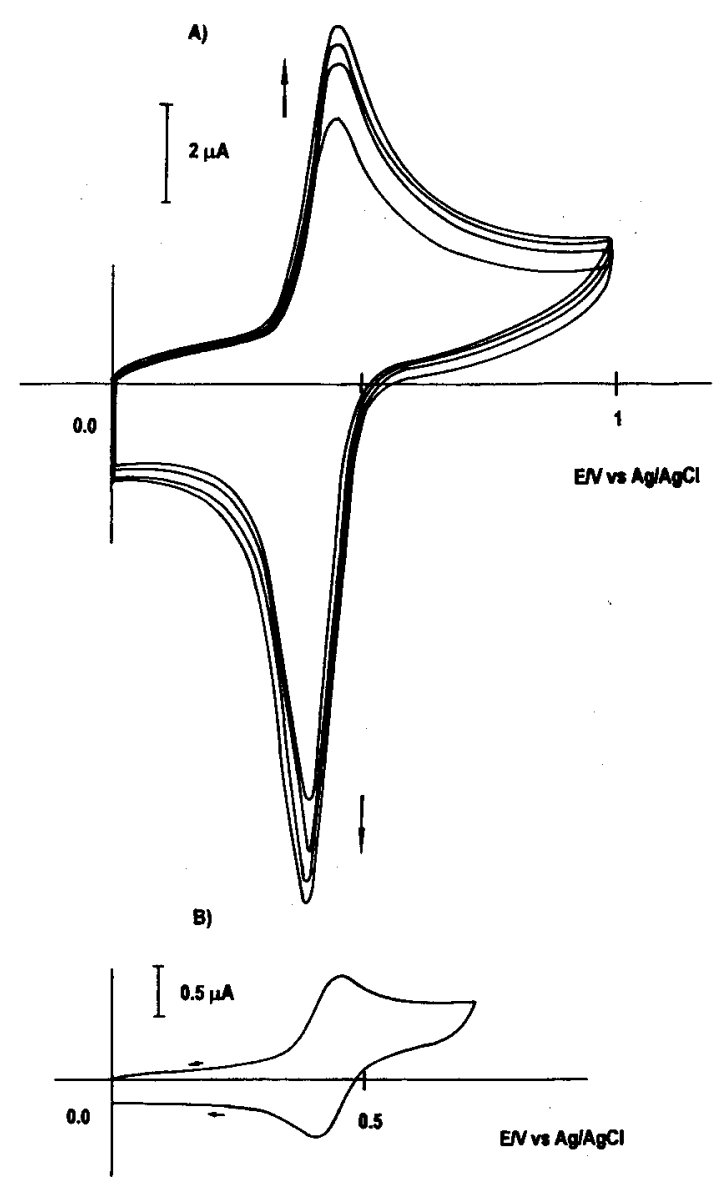

Figure 1. Cyclic voltammograms for $F A^{+}$at an $A Q 55$-coated glassy carbon electrode (A) and at a bare glassy carbon electrode (B). Voltammograms are shown for four different times during the $\mathrm{FA}^{+}$ loading process in $A(2,5,10$, and $15 \mathrm{~min})$. Scan rate, $100 \mathrm{mV} \mathrm{s}^{-1}$; $\left[\mathrm{FA}^{+}\right]=5 \times 10^{-5} \mathrm{M}$; supporting electrolyte, $0.1 \mathrm{M} \mathrm{KCl}$.

$\mathrm{FA}^{+}$partitioned into the film. These data can be used to calculate the equilibrium concentration (in terms of mole fraction of $\mathrm{SO}_{3}{ }^{-}$ sites occupied) of $\mathrm{FA}^{+}$in the film. A plot of the equilibrium film concentration vs the concentration of $\mathrm{FA}^{+}$in the aqueous solution used to load the film (i.e., a partition isotherm) is shown in Figure 2. The slope of such a plot is the partition coefficient, $K$, for the electroactive cation into the polymer film. ${ }^{4} \mathrm{~K}$ values for $\mathrm{FA}^{+}$in three different electrolytes and at two different electrolyte concentrations are shown in Table 1.

Table 1 indicates that the AQ 55 film shows high affinity for the hydrophobic cation $\mathrm{FA}^{+}$relative to the simple inorganic cations $\mathrm{Li}^{+}, \mathrm{Na}^{+}$, and $\mathrm{K}^{+}$. For example, a $\mathrm{K}$ of 1610 is obtained for the partitioning of $\mathrm{FA}^{+}$into a film from $10^{-3} \mathrm{M} \mathrm{LiClO}_{4}$. The dependence of the $\mathrm{K}$ value on the nature of the cation of the supporting electrolyte (Table 1) can be understood in terms of the extractability of the competing inorganic cation. The cation with the smallest hydration energy, $\mathrm{K}^{+}$, is the most extractable and, therefore, offers the highest competition with $\mathrm{FA}^{+}$; the cation with the highest hydration energy, $\mathrm{Li}^{+}$, is the least extractable and, therefore, shows the lowest competition. The increase in $\mathrm{K}$ with decreasing electrolyte concentration is simply a mass action effect. ${ }^{4}$ This effect is also expected, since $\mathrm{K}$ does not account for the fact that the partition process is, in reality, an ion-exchange reaction. ${ }^{4}$

It is of interest to compare these $K$ values to analogous values obtained for the well-known cation-exchange polymer $\mathrm{N}$ afion. ${ }^{4} \mathrm{As}$

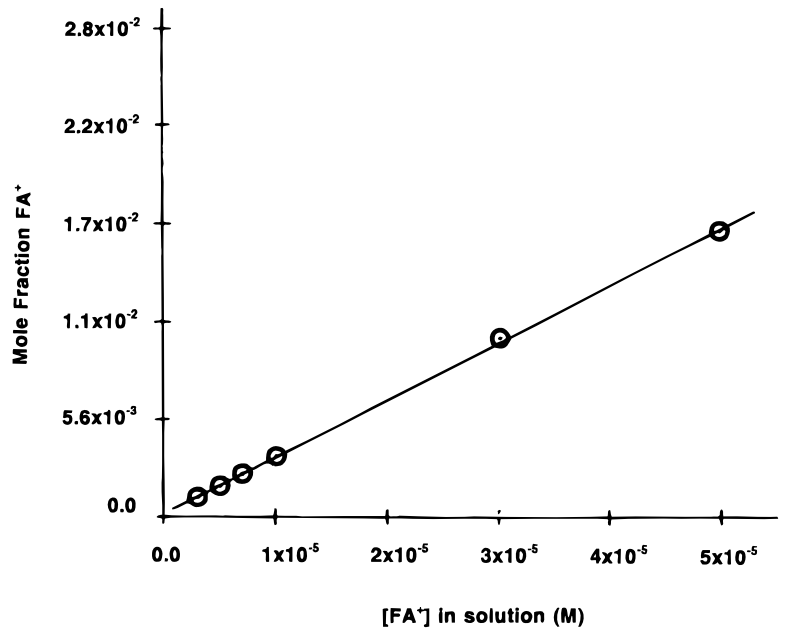

Figure 2. Partition isotherm for $\mathrm{FA}^{+}$in an $\mathrm{AQ} 55$ film coated onto a glassy carbon electrode. Data obtained from $5 \mathrm{mV} \mathrm{s}^{-1}$ scans. Supporting electrolyte, $0.1 \mathrm{M} \mathrm{NaNO}_{3}$.

Table 1. Partition Coefficients $(K)$ for the Ion-Exchange Preconcentration of $\mathrm{FA}^{+}$into $\mathrm{AQ} 55$

Films Coated onto Glassy Carbon Macroelectrodes

\begin{tabular}{cr} 
supporting electrolyte (concn, M ) & \multicolumn{1}{c}{ K } \\
$\mathrm{LiClO}_{4}\left(1 \times 10^{-1}\right)$ & 510 \\
$\mathrm{NaNO}_{3}\left(1 \times 10^{-1}\right)$ & 290 \\
$\mathrm{KNO}_{3}\left(1 \times 10^{-1}\right)$ & 208 \\
$\mathrm{LiClO}_{4}\left(1 \times 10^{-3}\right)$ & 1370 \\
$\mathrm{NaNO}_{3}\left(1 \times 10^{-3}\right)$ & 960 \\
$\mathrm{KNO}_{3}\left(1 \times 10^{-3}\right)$ & 690
\end{tabular}

indicated in Table $1, A Q 55$ shows $K=340$ when $\mathrm{FA}^{+}$is loaded from $0.1 \mathrm{M} \mathrm{NaNO}_{3}$. Nafion shows $\mathrm{K}=1.1 \times 10^{6}$ when $\mathrm{FA}^{+}$is loaded from $0.1 \mathrm{M} \mathrm{NaClO}_{4}{ }^{4}$ Hence, $\mathrm{Nafion}$ shows even greater preference for this hydrophobic cation. It is well known that $\mathrm{N}$ afion shows extraordinary ion-exchange affinity for such hydrophobic cations. ${ }^{4,12}$

Figure 3 shows a typical calibration curve for $\mathrm{FA}^{+}$at the $\mathrm{AQ}$ 55-coated glassy carbon electrode. The slopes of such calibration curves depend, of course, on the nature and concentration of the supporting electrolyte used (Table 1). To define the detection limit, we obtained five replicate measurements of the background signal $\left(\mathrm{no} \mathrm{FA}^{+}\right.$) at the potential corresponding to the $\mathrm{FA}^{+}$peak. The standard deviation $(\sigma)$ for this measurement of the background signal (equivalent to the background noise) was calculated. The detection limit (DL) was then defined as per the IUPAC recommendation, ${ }^{13}$

$$
\mathrm{DL}=3 \sigma / \mathrm{m}
$$

where $m$ is the slope of the calibration curve. A detection limit of $4.2 \times 10^{-7} \mathrm{M}$ was calculated from the calibration curve in Figure $3(\sigma=30 \mathrm{nA} ; \mathrm{m}=0.215 \mathrm{~A} / \mathrm{M})$.

Preconcentration of $\mathrm{Ru}\left(\mathrm{NH}_{3}\right)_{6}{ }^{3+}$ at the Coated Glassy Carbon Electrode. As was the case with $\mathrm{FA}^{+}, \mathrm{Ru}\left(\mathrm{NH}_{3}\right)_{6}{ }^{3+}$ is also preconcentrated into the $\mathrm{AQ} 55$ film. Longer times (relative to $\mathrm{FA}^{+}$) are required to reach maximal loading of $\mathrm{Ru}\left(\mathrm{NH}_{3}\right)_{6}{ }^{3+}$ into the films, and higher loading levels of $\mathrm{Ru}\left(\mathrm{NH}_{3}\right)_{6}{ }^{3+}$ are achieved.

(12) M artin, C. R.; Freiser, H. Anal. Chem. 1981, 53, 902-904.

(13) Long, G. L.; Winefordner, J. D. Anal. Chem. 1983, 55, 712A-724A. 


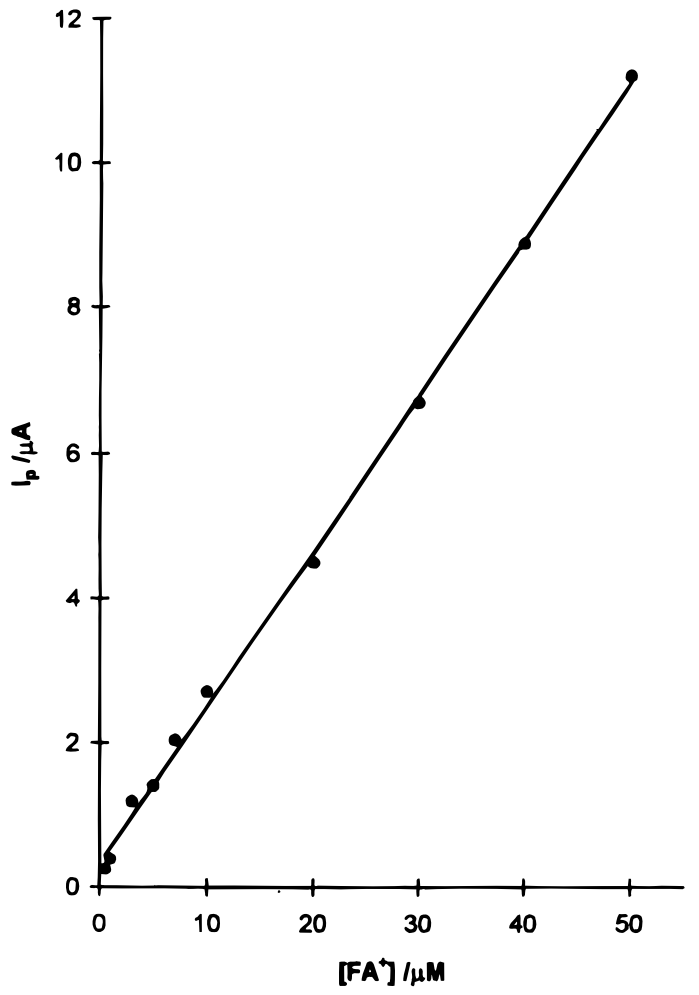

Figure 3. Calibration curve for $\mathrm{FA}^{+}$at an $\mathrm{AQ}$ 55-coated glassy carbon electrode. Scan rate, $100 \mathrm{mV} \mathrm{s}^{-1}$; supporting electrolyte, $10^{-3}$ $\mathrm{M} \mathrm{NaNO}_{3}$.

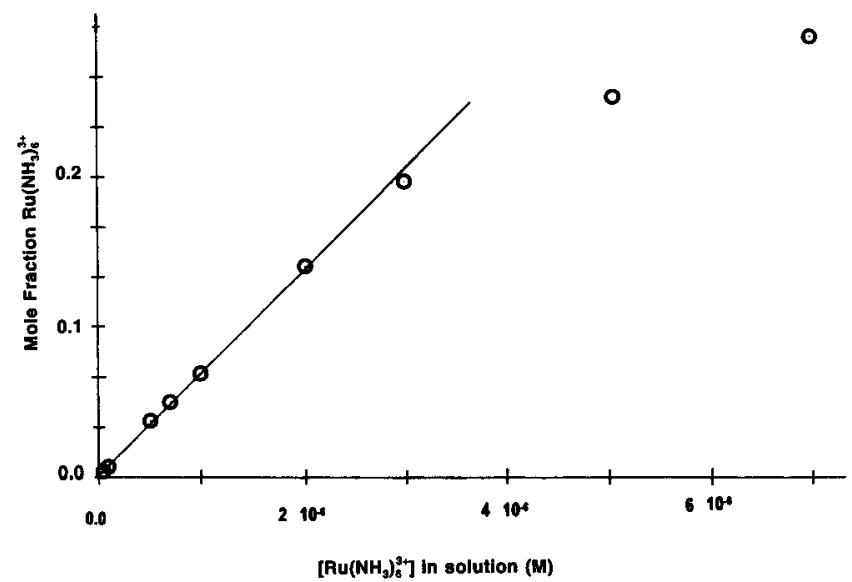

Figure 4. Partition isotherm for $\mathrm{Ru}\left(\mathrm{NH}_{3}\right)_{6}{ }^{3+}$ at the $A Q$ 55-coated glassy carbon electrode. Scan rate, $5 \mathrm{mV} \mathrm{s}^{-1}$; supporting electrolyte, $0.1 \mathrm{M} \mathrm{KCl}$.

Integration of the slow-scan (5 $\left.\mathrm{mV} \mathrm{s}^{-1}\right)$, maximal-loading voltammograms again yields the partition isotherm (Figure 4). The Ru$\left(\mathrm{NH}_{3}\right)_{6}{ }^{3+}$ isotherms are linear at low solution concentrations but show the effects of saturation of the AQ 55 film at higher concentrations.

A partition coefficient of $7.2 \times 10^{4}$ is obtained from the linear part of the $\mathrm{Ru}\left(\mathrm{NH}_{3}\right)_{6}{ }^{3+}$ isotherm in Figure 4. These data indicate that $\mathrm{AQ} 55$ shows stronger ion-exchange affinity for $\mathrm{Ru}\left(\mathrm{NH}_{3}\right)_{6}{ }^{3+}$ than for $\mathrm{FA}^{+}$. This is why the $\mathrm{Ru}\left(\mathrm{NH}_{3}\right)_{6}{ }^{3+}$ isotherm shows the effect of saturation (curvature at high concentration, Figure 4), whereas the $\mathrm{FA}^{+}$isotherm does not (Figure 2). As was the case for $\mathrm{FA}^{+}$, the partition coefficient for $\mathrm{Ru}\left(\mathrm{NH}_{3}\right)_{6}{ }^{3+}$ in $\mathrm{AQ} 55$ is lower than the $\mathrm{Ru}\left(\mathrm{NH}_{3}\right)_{6}{ }^{3+}$ partition coefficient in Nafion $(\mathrm{K}=2.5 \times$ $\left.{ }^{10}{ }^{6}\right) .{ }^{4}$ As might be expected from the partition data, the Ru$\left(\mathrm{NH}_{3}\right)_{6}{ }^{3+}$ calibration curve (not shown) has a lower detection limit

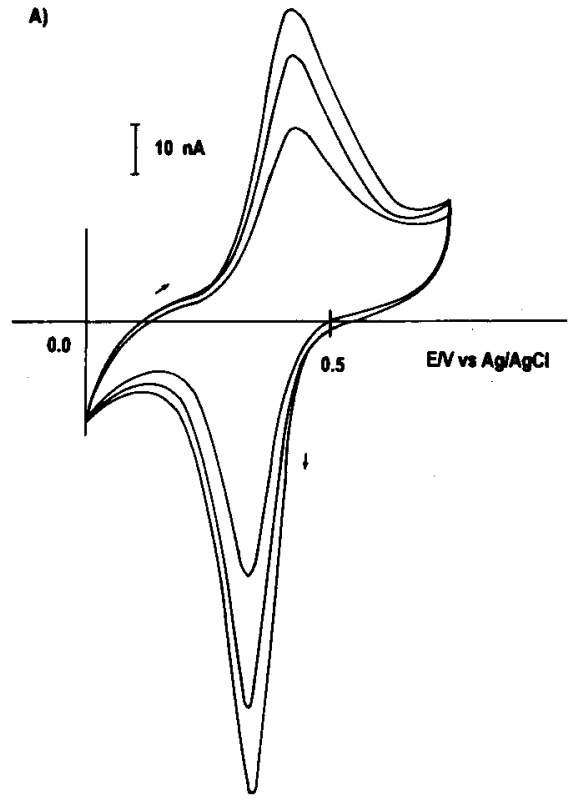

B)

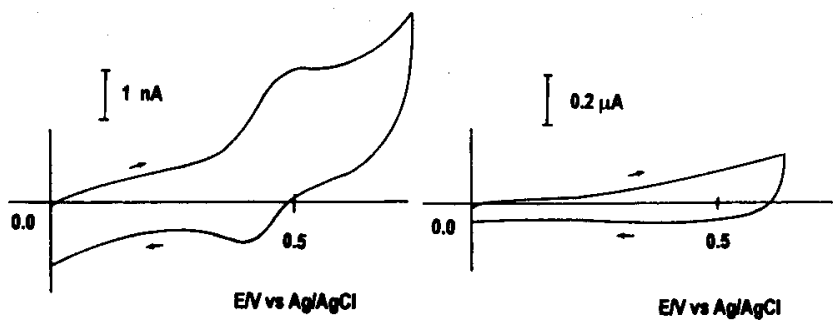

Figure 5. Cyclic voltammograms for $1 \times 10^{-7} \mathrm{M} \mathrm{FA}^{+}$in $1 \times 10^{-3}$ $\mathrm{M} \mathrm{NaNO}_{3} . \quad v=20 \mathrm{mV} \mathrm{s}^{-1}$. (A) AQ 55-coated NEE. Voltammograms recorded every $15 \mathrm{~min}$ during loading. (B) Uncoated NEE. (C) Uncoated Au macroelectrode.

$\left(2.7 \times 10^{-8} \mathrm{M}\right)$ than the $\mathrm{FA}^{+}$calibration curve. The sensitivity (3.3 A/M) is also higher. However, because of the saturation effect seen in the isotherm at higher concentrations (Figure 4), the linear part of the $\mathrm{Ru}\left(\mathrm{NH}_{3}\right)_{6}{ }^{3+}$ calibration curve does not extend to as high concentrations as does the $\mathrm{FA}^{+}$calibration curve.

AQ 55 Film-Coated NEEs. Figure $5 A$ shows $\mathrm{FA}^{+}$loading voltammograms for an AQ 55 film-coated NEE after immersion into a solution that was $1 \times 10^{-7} \mathrm{M}$ in $\mathrm{FA}^{+}$. M aximal loading of the film with $\mathrm{FA}^{+}$occurs after $\sim 75 \mathrm{~min}$. The voltammograms at the uncoated NEE and at an Au macroelectrode are shown in Figure $5 B$ and $C$, respectively. A comparison of the various voltammograms in Figure 5 shows that the sensitivity at the $A Q$ 55-coated NEE is dramatically improved over that observed at the uncoated NEE (note the difference in current sensitivity in Figure $5 \mathrm{~A}$ and $\mathrm{B})$ and at the Au macroelectrode.

To quantitatively evaluate this improvement in sensitivity, calibration curves for $\mathrm{FA}^{+}$and $\mathrm{Ru}\left(\mathrm{NH}_{3}\right)_{6}{ }^{3+}$ were obtained at the polymer-coated NEEs. The AQ 55-coated NEE was first equilibrated in a solution of the desired concentration of the desired electroactive cation, and a voltammogram was recorded at a scan rate of $20 \mathrm{mV} \mathrm{s}^{-1}$. Peak currents were plotted, as before, vs concentration of the electroactive ion in the solution phase. The resulting calibration (Figure 6 ) is linear over a wide dynamic range and shows a detection limit (defined as above) of $5 \times 10^{-9} \mathrm{M}$. This detection limit observed at the AQ 55-coated NEE is over 2 orders of magnitude lower than that observed at the coated macroelectrode and over 1 order of magnitude lower than the detection limit at the uncoated NEE (see Table 2). 


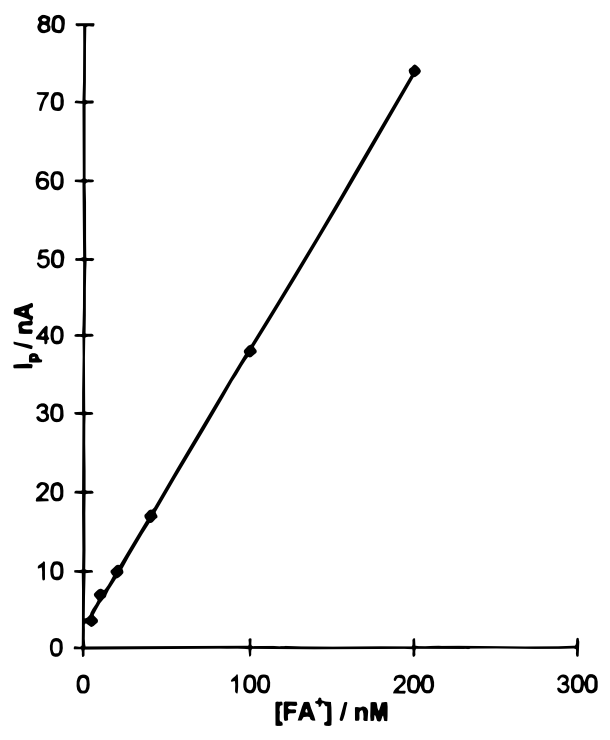

Figure 6. Calibration curve for $\mathrm{FA}^{+}$at the $\mathrm{AQ}$ 55-coated NEE. Supporting electrolyte, $1 \times 10^{-3} \mathrm{M} \mathrm{LiClO}_{4}$; scan rate, $20 \mathrm{mV} \mathrm{s}^{-1}$.

Table 2. Comparison of Cyclic Voltammetric Detection Limits for $\mathrm{FA}^{+}$and $\mathrm{Ru}\left(\mathrm{NH}_{3}\right)_{6}{ }^{3+}$ at an Uncoated Macroelectrode, an Uncoated NEE, and an AQ 55-Coated NEE

\begin{tabular}{lcc} 
& \multicolumn{2}{c}{ detection limit (M) } \\
\cline { 2 - 3 } \multicolumn{1}{c}{ electrode } & $\mathrm{FA}^{+}$ & $\mathrm{Ru}\left(\mathrm{NH}_{3}\right)_{6} 6^{3+}$ \\
bare macroelectrode & $2 \times 10^{-5}$ & $2 \times 10^{-5}$ \\
bare NEE & $5 \times 10^{-8}$ & $7 \times 10^{-8}$ \\
AQ 55-coated NEE & $5 \times 10^{-9}$ & $6 \times 10^{-0}\left(1 \times 10^{-9}\right)^{\mathrm{a}}$ \\
& \\
a By differential pulse voltammetry. & \\
\hline
\end{tabular}

Analogous data were obtained for $\mathrm{Ru}\left(\mathrm{NH}_{3}\right)_{6}{ }^{3+}$ at the AQ-55 coated electrode. The detection limit for $\mathrm{Ru}\left(\mathrm{NH}_{3}\right)_{6}{ }^{3+}$ is somewhat higher than the detection limit for $\mathrm{FA}^{+}$due to the proximity of the $\mathrm{Ru}\left(\mathrm{NH}_{3}\right)_{6}{ }^{3+}$ voltammogram to the negative limit of the potential window for the Au NEEs studied here. This causes the background current, and noise level, to be higher for $\mathrm{Ru}\left(\mathrm{NH}_{3}\right)_{6}{ }^{3+}$ at the NEE. Nevertheless, the detection limit for $\mathrm{Ru}\left(\mathrm{NH}_{3}\right)_{6}{ }^{3+}$ at the AQ 55-coated NEE is lower than that observed at either the coated macroelectrode or the uncoated NEE (Table 2). The detection limit for $\mathrm{Ru}\left(\mathrm{NH}_{3}\right)_{6}{ }^{3+}$ can be lowered further by differential pulse voltammetry, in order to discriminate against background, at the AQ 55-coated NEE. With differential pulse voltammetry, a detection limit of $1 \times 10^{-9} \mathrm{M}$ for $\mathrm{Ru}\left(\mathrm{NH}_{3}\right)_{6}{ }^{3+}$ at the polymer-coated NEE was obtained.

E lectrode-to-E lectrode Reproducibility. The reproducibility of the voltammetric current from one film-coated NEE to another was quite good. For example, four different film-coated NEEs that had been equilibrated with $1 \times 10^{-7} \mathrm{M} \mathrm{FA}^{+}$in $0.001 \mathrm{M} \mathrm{NaNO}_{3}$ (supporting electrolyte) yielded equilibrium peak currents of 12.4, $12.5,11.6$, and $13.1 \mathrm{nA}$. This corresponds to a relative standard deviation of $5 \%$ This excellent reproducibility in the electrodeto-electrode response can be attributed to the excellent reproducibility of the film formation method.

Effect of Supporting Electrolyte Concentration on the Shape of the Voltammetric Wave at the AQ 55-Coated NEE. In the earlier investigations of the uncoated NEEs, an unusual effect of the concentration of supporting electrolyte on the shape of the voltammogram was discovered. ${ }^{1}$ The voltammetric wave

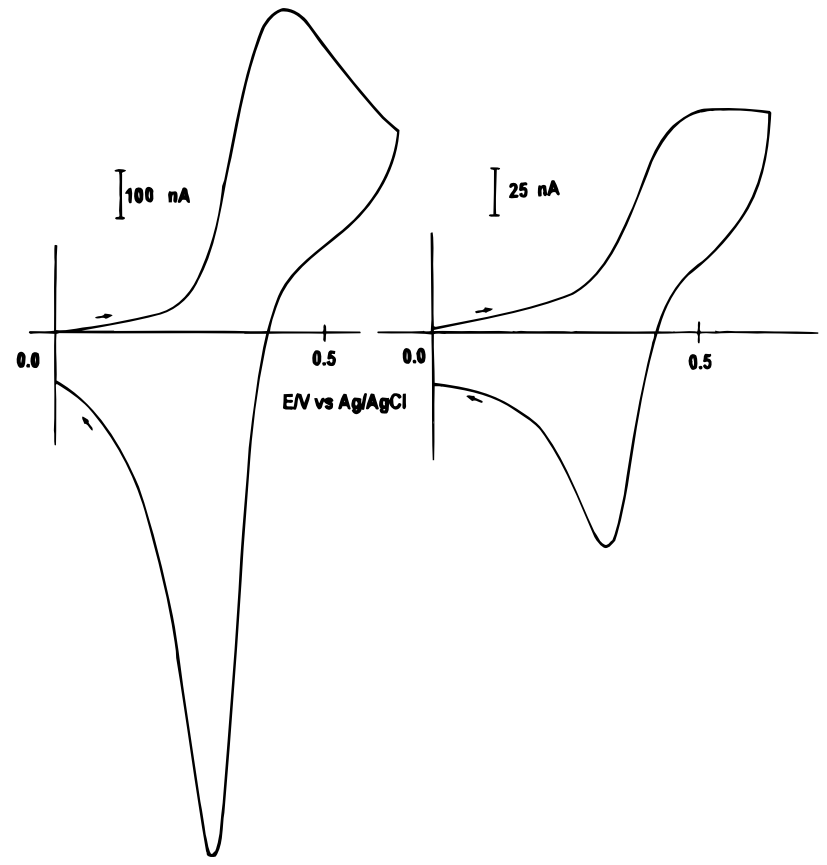

Figure 7. Cyclic voltammograms recorded in $1 \times 10^{-6} \mathrm{M} \mathrm{FA}^{+}$ solutions, in $0.1 \mathrm{M}$ and $10^{-3} \mathrm{M} \mathrm{NaNO}_{3}$ at $\mathrm{AQ} 55$-coated NEE. Scan rate, $20 \mathrm{mV} \mathrm{s}^{-1}$.

for a number of fast redox couples flattened, and the peak separation became larger as the concentration of supporting electrolyte was increased. This is an unusual effect, because voltammetric waves often appear more reversible when higher supporting electrolyte concentrations are used. This is because broadening due to solution resistance is minimized at high electrolyte concentrations. At the NEEs, the voltammetric wave looks less reversible as the concentration of supporting electrolyte increases. ${ }^{1}$ Possible explanations for this unusual effect of supporting electrolyte concentration at the NEEs are discussed in a forthcoming paper. ${ }^{14}$

Suffice it to say here that this electrolyte concentration effect is also observed at the AQ 55-coated NEE. Figure 7 compares $\mathrm{FA}^{+}$voltammograms at electrolyte $\left(\mathrm{NaNO}_{3}\right)$ concentrations of 1 $\mathrm{mM}$ and $0.1 \mathrm{M}$. The decrease in current at the higher electrolyte concentration is expected due to greater ion-exchange competition from the $\mathrm{Na}^{+}$of the electrolyte. Note, however, that the voltammetric waves appear distorted at the higher electrolyte concentration, particularly the forward wave. This effect was observed at the polymer-coated NEEs for both of the redox couples investigated here.

This unusual electrolyte effect has implications for possible analytical applications of the polymer-coated NEEs. These data suggest that it would be better to do analyses at the polymercoated NEEs at low electrolyte concentrations, since this results in less distortion and broadening of the voltammetric waves. Furthermore, the partition coefficient for the electroactive ion is greatest at low electrolyte concentrations (Table 1). Hence, there are two reasons why low electrolyte concentrations are desirable at the polymer-coated NEEs. Fortunately, because currents at the NEEs are low (particularly at low concentrations of electroactive species), using a low electrolyte concentration is not a problem at the NEEs. ${ }^{1}$

(14) Martin, C. R.; M enon, V. P. M anuscript in preparation. 


\section{CONCLUSIONS}

We have demonstrated that the enhancements in electrochemical detection limits inherent in the nanoelectrode ensemble can be further amplified by coating the NEE with a thin film of the ion-exchange polymer AQ 55. This is, to our knowledge, the first paper describing the electrochemistry and the analytical advantages of polymer film-coated nanoelectrode ensembles.

\section{ACKNOWLEDGMENT}

This work was supported by CNR (Rome) and the U.S. Office of Naval Research. Collaboration between the University of
Venice and Colorado State University was made possible by a Collaborative Research Grant from NATO (Brussels). We acknowledge Danilo Rudello for technical assistance in the filmcoating procedure.

Received for review June 12, 1996. Accepted September $18,1996 .^{\otimes}$

\section{AC960580B}

${ }^{\otimes}$ Abstract published in Advance ACS Abstracts, November 1, 1996. 